\title{
SECONDARY GLAUCOMA DUE TO SPONTANEOUS RUPTURE OF THE LENS CAPSULE*.
}

\author{
BY \\ F. S. HUBBERSTY AND J. S. GOURLAY \\ From the North Riding Infirmary, Middlesbrough, Yorkshire
}

\section{GIFFORD (1900) remarked :}

It may be safely said that while everyone would develop a senile cataract if he lived long enough ; so also would everyone obtain a spontaneous cure, if life were sufficiently prolonged.

The frequency with which the spontaneous cure of senile cataract is complicated by glaucoma was noted initially by Szily (1884), and glaucoma occurred in eight and iritis or iridocyclitis in three of the 34 cases discussed by Reuss (1900).

Gifford (1900) described four cases of spontaneous cure of cataract, in three of which the vision had been lost through glaucoma. Nevertheless, during the following 18 years he encountered only four more cases.

Recently Sugar (1949), when reporting three cases of glaucoma following rupture of the lens capsule, mentioned that this condition was not included in his elaborate and comprehensive classification not only because he had never encountered this condition, but also because of the difficulty in determining the cause of glaucoma.

Instances of this condition are cited also by Rollet and Genet (1913), Gonzalez (1919), Daily (1933), and Knapp (1937).

\section{ICase Reports}

In the last 2 years, four cases of glaucoma secondary to rupture of the lens capsule have been encountered:

(1) Male, aged 77, attended on December 18, 1950. The right eye had been painful for the past month and when examined showed circumcorneal injection with corneal oedema and raised tension $(45 \mathrm{~mm}$. $\mathrm{Hg}$ Schiötz). The anterior chamber was full of scintillating particles and also presented the appearance of a hypopyon. The vision was reduced to perception of light. Cataract extraction had been performed on the left eye some years before, and visual acuity was $6 / 9$ in the left eye with correction.

Paracentesis was performed with a fine hollow needle and many cholesterol crystals were identified in the aspirate. On the following day gonioscopy was attempted but was not practicable owing to rapid onset of corneal oedema. Paracentesis was again performed.

On December 22 an intracapsular cataract extraction was successfully performed by one of us (F.S.H.) and an uneventful convalescence ensued. The immediate visual result was $6 / 60$, but 4 months later this had improved to $6 / 18$ despite definite pallor of the optic disc.

(2) Male, aged 75, attended on January 6, 1952, complaining of pain in the left eye of 2

- Received for publication January 12, 1953. 
days duration. Before this, vision had been reduced to perception of light by a cataract which had been present for some 20 years. The eye was convergent. There was considerable ciliary congestion and corneal oedema with a raised ocular tension $(55 \mathrm{~mm}$. $\mathrm{Hg}$ Schiötz), but the striking feature was that the anterior chamber was completely filled with a milky fluid. The condition improved markedly with atropine and heat; when the eye was examined subsequently by one of us the lower half of the cornea was rendered opaque by coalescing spots of white debris, and numerous iridescent crystals were circulating in the anterior chamber. The vessels of an atrophic iris were markedly engorged and the diagnosis was made of a ruptured hypermature cataract. Four days later the tension had returned to normal. Gonioscopy showed the filtration angle to be widely open and many glistening crystals were seen to be enmeshed in the trabeculum. Paracentesis confirmed that the crystals seen were cholesterol. The protein content of the aqueous was high. Intradermal injection of fresh lens protein gave negative results.

Subsequent progress was uneventful and at the time of discharge the capsule was shrunken and opaque and still contained a residue of lens matter. No rent was seenat this stage.

This patient was seen again recently with a recurrence of the glaucoma and two small rents were noted in the anterior capsule through which lens matter was escaping.

Since the inflammation and the rise in tension again rapidly subsided with atropine and heat, operative intervention was felt to be unnecessary.

(3) Female, aged 83, was admitted on January 24, 1952, with a subacute secondary glaucoma in the left eye which had been cataractous for some years. The right eye was aphakic. The affected eye showed moderate dilatation of the pupil, a steamy cornea, and a pseudo-hypopyon. When the cornea was cleared with glycerine many shimmering particles were observed in the anterior chamber together with a doubtful dehiscence of the capsule at $60^{\circ}$ clock. Paracentesis was performed, and the aqueous was found to contain many cholesterol crystals and much protein. Gonioscopy could not be performed owing to the rapid rise in tension and a turbid aqueous. The following day an extracapsular cataract extraction was performed, in the course of which the tiny nucleus became lodged under the iris at 12 o'clock and a complete iridectomy became necessary to facilitate delivery.

During convalescence, which was uneventful, intradermal injections of fresh lens protein were made with negative results.

On discharge, a fortnight later, the eye was white, the fundus appeared normal, and the visual acuity was 618 with correction.

(4) Female, aged 60, was sent into hospital on August 2, 1951, with a diagnosis of acute glaucoma. She was a known diabetic and had undergone a cataract operation on the right eye at the age of 46 . The corrected visual acuity in the right eye was $6 / 12$. The sight in the left eye had gradually failed and it had been virtually blind for some years.

After a number of transient premonitory attacks this eye had become painful and congested 10 days earlier, and on admission the diagnosis of glaucoma was confirmed, the iris showed tangential vascularization, and the small brown lens nucleus lay at the bottom of the anterior chamber. Slit-lamp examination revealed a wide horizontal rent in the capsule.

The tersion resolved under eserine and on the following day the nucleus was removed through a keratome incision by one of us (J.S.G.) under pantocaine anaesthesia. Despite good eserine miosis, the iris dilated on withdrawal of the keratome and the nucleus promptly vanished through the pupillary aperture. The patient was turned over, and the nucleus reappeared and was removed by a vectis.

Convalescence was uneventful, and despite partial occlusion of the pupil by the anterior lens capsule which lay rolled up horizontally like a glass membrane, together with marked pallor and cupping of the optic disc, the corrected vision was $6 / 24$. 


\section{Discussion}

It is probable with an ageing population that this condition will be encountered more frequently than in the immediate past, although it would not appear to have been uncommon in the terminal decades of the 19th century, when Gifford (1900) stressed the danger of leaving a cataract to become hypermature.

Depending on two factors, the site and extent of the capsular dehiscence and the state of the capsular contents, the clinical picture will vary between, on the one hand, a quiet symptomless absorption of the lens, in all probability through a minute rent in the posterior capsule, and, on the other hand, mass expulsion of degenerate lens matter into the anterior chamber with immediate and arresting consequences.

The appearance of a hypopyon in a congested and glaucomatous eye which has been blind for years is not encouraging, and if the condition is unrecognized will almost certainly result in loss of vision and probably of the eye itself. But as Rychener (1950) remarked in a recent symposium on secondary glaucoma :

One is always hesitant to do an intra-ocular procedure on an acutely inflamed eye. Some such hypermature cataracts will cause inflammatory symptoms due to dehiscence of the lens capsule or actual rupture of the capsule. One may see such eyes before glaucoma complicates matters, and removal of the lens should be done at once. If glaucoma is present and the pressure is under $40 \mathrm{~mm}$. Hg Schiötz, I do not hesitate to do a combined extraction. As a matter of fact, I have seen some eyes lost to malignant glaucoma which might have been salvaged if the surgeon had been less timid. Some such eyes have an exudate in the anterior chamber resembling hypopyon. It is amazing how such eyes clear with removal of the hypermature cataract.

In the four cases reported above, paracentesis was found to be of considerable assistance in effecting temporary lowering of tension, in evacuating irritant material which obscured the eye, and for diagnostic purposes. The tension, however, usually rises again quite soon with the extrusion of further lens matter into the anterior chamber. In Case 3 it was felt that no useful purpose was to be served by further operative intervention on a convergent eye ; but in two instances removal of the hypermature cataract was effected with gratifying results. The lens nucleus in these cases is usually very small and an extra-capsular extraction through a small incision would appear to be the best method.

Sugar (1949) is of the opinion that the many cases of spontaneous absorption of cataract reported in the literature may in all probability be attributed to a rent in the posterior lens capsule, and that the particles of lens matter are held back by the zonule. The frequent occurrence of glaucoma and uveitis in these cases strengthens this view. Cases of rupture of the anterior lens capsule are few, and three possible causes are suggested for the accompanying glaucoma :

(1) Chemical irritation due to the toxic by-products of lens hydrolysis.

(2) Increased osmotic pressure.

(3) Mechanical obstruction affecting the aqueous outflow. 
The first he regards as the only common factor in his three cases, and these are accordingly classified as secondary glaucomas under Group 1 (overproduction of aqueous resulting from irritation of the ciliary processes).

According to Duke-Elder (1940), the tension is probably due to congestion which is principally neuro-vascular and possibly allergic, aided by minor blockage of the drainage channels.

In the only case reported above which permitted gonioscopy, the filtration angle was seen to be widely open. Davson (1949), in discussing lens proteins, points out that in the normal lens the $\beta$ and $\gamma$ crystallines neutralize the $\alpha$ crystallines, and consequently lens rupture is not followed by an immune reaction. If, however, this balance is upset, i.e. in cataract, the individual may become sensitized to the $\alpha$ crystalline and a further injection of lens protein may lead to an anaphylactic response.

Differential Diagnosis. - The very acute cases in which the anterior chamber is suddenly flooded with liquefied lens cortex may resemble purulent endophthalmitis. A history of blindness due to cataract of several years' duration and a light grey colour of the contents of the anterior chamber suggest a rupture of the lens capsule. After aspiration of the aqueous it may be possible to see a rent in the capsule, and microscopic examination of the aqueous may show cholesterol crystals derived from degenerate lens cortex. The more chronic cases resemble cyclitis with secondary cataract. Deposits on the back of the cornea due to inflammation are sometimes very hard to distinguish from deposits of lens matter, and the diagnosis depends largely upon the finding of a hole in the lens capsule.

The foregoing experience has led us to warn patients, as did Gifford (1900), of the danger they run in allowing a cataract to become hypermature, and we advise such cases to undergo early operation whether or not a cataract has been removed from the other eye.

\section{Summary}

(1) Satisfactory operative results are described in three out of four cases of secondary glaucoma due to spontaneous rupture of the anterior lens capsule.

(2) It is recommended that whenever possible this condition should be anticipated by removal of the hypermature cataract.

We wish to express our obligation to Mr. A. E. P. Parker for permission to record two cases.

\section{REFERENCES}

DAILY, R. K. (1933). Sth. med. J., Bgham, Ala., 26, 396.

Davson, H. (1949). " The Physiology of the Eye." Churchill, London.

DUKE-ELDER, S. (1940). "Text-book of Ophthalmology", vol. 3, p. 3171. Kimpton, London.

GIFFORD, H. (1900). Amer. J. Ophthal., 17, 289.

GonZALEZ, J. de J. (1919). Ibid., 2, 743.

KNAPP, H. C. (1937). Ibid., 20, 820.

Reuss, A. von (1900). Z Zbl. prakt. Augenheilk., 24, 33.

Rollet and GeNeT (1913). Rev. gén. ophtal., Paris, 32, 1.

RYCHENER, R. O. (1950). Amer. J. Ophthal., 33, 1666.

SUGAR, H. S. (1949). Ibid., 32, 1509.

SzILY, A. (1884). Z Zbl. prakt. Augenheilk., 8, 17. 